\title{
Digital games in health professions education: Advantages, disadvantages, and game engagement factors
}

\author{
Shoaleh Bigdeli ${ }^{1 *}$, David Kaufman ${ }^{2}$ \\ Received: 3 Apr $2016 \quad$ Published: 22 Dec 2017
}

\begin{abstract}
Background: The application of digital educational games in health professions education is on expansion and game-based education usage is increasing.

Methods: Diverse databases were searched and the related papers were reviewed.

Results: Considering the growing popularity of educational games in medical education, we attempted to classify their benefits, flaws, and engaging factors.

Conclusion: Advantages, disadvantages, and engagement factors of educational digital games used for health professions education must be the focus of attention in designing games for health professions discipline.
\end{abstract}

Keywords: Game, Advantages, Disadvantages, Game engagement factors, Health professions education

Copyright $\bigcirc$ Iran University of Medical Sciences

Cite this article as: Bigdeli Sh, Kaufman D. Digital games in health professions education: Advantages, disadvantages, and game engagement factors. Med J Islam Repub Iran. 2017 (22 Dec);31:117. https://doi.org/10.14196/mjiri.31.117

\section{Introduction}

It is commonly acknowledged that a digital game can serve as a medium to promote health professions and provide an opportunity for interdisciplinary education. In particular, the essential elements of games (1-3) and game attributes of the player/players, conflicts, rules, predetermined goals of the game, the artificial (4) and the pedagogic nature of games (5) are extensively described in the literature.

Despite the increasing popularity of digital games, the emphasis on their positive educational advantages over traditional teaching methods (5-7) and the opportunities provided for diverse preferred learning styles of learners (8), to the best of our knowledge, the findings on pedagogical applications are not conclusive in the literature. In health professions education, digital games are acknowledged as games, simulations, simulated games, virtual environments, social and cooperative plays, and alternative reality

Corresponding author: Dr Shoaleh Bigdeli, sbigdeli@alumni.sfu.ca

1. Center for Educational Research in Medical Sciences (CERMS), Department of Medical Education, Faculty of Medicine, Iran University of Medical Sciences, Tehran, Iran.

2. Faculty of Education, Simon Fraser University (SFU), Vancouver, BC, Canada. games $(5,6,9)$; however, there are some differences, but common advantages, disadvantages, and engaging factors involved.

Moreover, extensive research has been conducted on the application of digital games, but few provide a comprehensive classification based on advantages and disadvantages of games and their engaging factors. In this regard, this review study is a synopsis of the auspicious area of digital gaming, which explains its potential benefits, flaws, and engagement factors for introducing gamification as a medium to promote health professions education. This study is focused on digital games used in medicine, nursing, pharmacy, and dentistry education during 2010 to 2015, while other disciplines of health professions education were not the focus of concern.

$\uparrow$ What is "already known" in this topic:

The application of digital educational games is increasing in medical and health professions education.

\section{$\rightarrow$ What this article adds:}

Under the game conditions, stress-related physiological experience (eustress or distress) of digital game players are similar to the signs and symptoms of stress in other situations. Advantages of digital educational games can be categorized as learning process enhancer, learning and performance improver, and individualized learning provider. Disadvantages of digital educational games can be categorized into teaching-learning process barriers and logistics of educational games. 


\section{Methods}

This review study was conducted from September to December 2015 by reviewing peer-reviewed journal articles published in, CINAHL Complete, Cochrane Library (Cochrane CENTRAL and Cochrane Reviews), EBSCOhost, Elsevier Science Direct, ERIC, PsycINFO, PsycARTICLES, PubMed, PubMed Central (PMC), and PubMed/MEDLINE databases with the following search terms (AND, OR, NOT) and keywords: Game, gamified, gamification, computer game, digital game, electronic game, video game, systematic review, meta-analysis, meta-analysis, meta-analysis, health professions, medical, nursing, pharmacy, dentistry, education, advantages, benefits, disadvantages, flaws, and game engagement factors.

\section{Inclusion criteria}

Articles related to games were filtered and limited to fulltext peer-reviewed papers in English published during 2010 and 2015. It was also decided to include studies in which health professions learners were study participants, and in which digital games in health professions education disciplines of medicine, nursing, pharmacy and dentistry were addressed.

Titles and abstracts, resulting from the initial online search with the selected MeSH and free text terms related to digital educational games were screened for relevance and eligibility for full text retrieval. The researchers searched additional articles through citation by manual checking of the reference sections of the sourced articles. The researchers resolved their disagreements by discussion. Finally, articles focusing on the use of specific educational games for health professions education disciplines of medicine, nursing, pharmacy and dentistry were retrieved.

\section{Exclusion Criteria}

The articles were excluded under the following conditions, not available in full text; if the participants were residency learners and/or health professionals only (e.g., surgeons, specialists, etc.); patients, teachers and/or staff only; the studies addressing blogs, discussion boards, podcasts, videos and videoconferencing; non-digital games; the studies on apps for smart phones, tablets, and portable music players; the studies on topics of patient management, patient education, teacher and staff education.

\section{Results}

According to the findings of the study, advantages and disadvantages of games have been the topic of dispute ( 7 , 8, 10-26). Further, an educational game as an engaging, competitive, motivating, and pleasurable activity with specified sets of rules and regulations and other common elements of feedback, challenge, and interaction promotes

Table 1. Digital educational game advantages for teaching and learning in health professions education

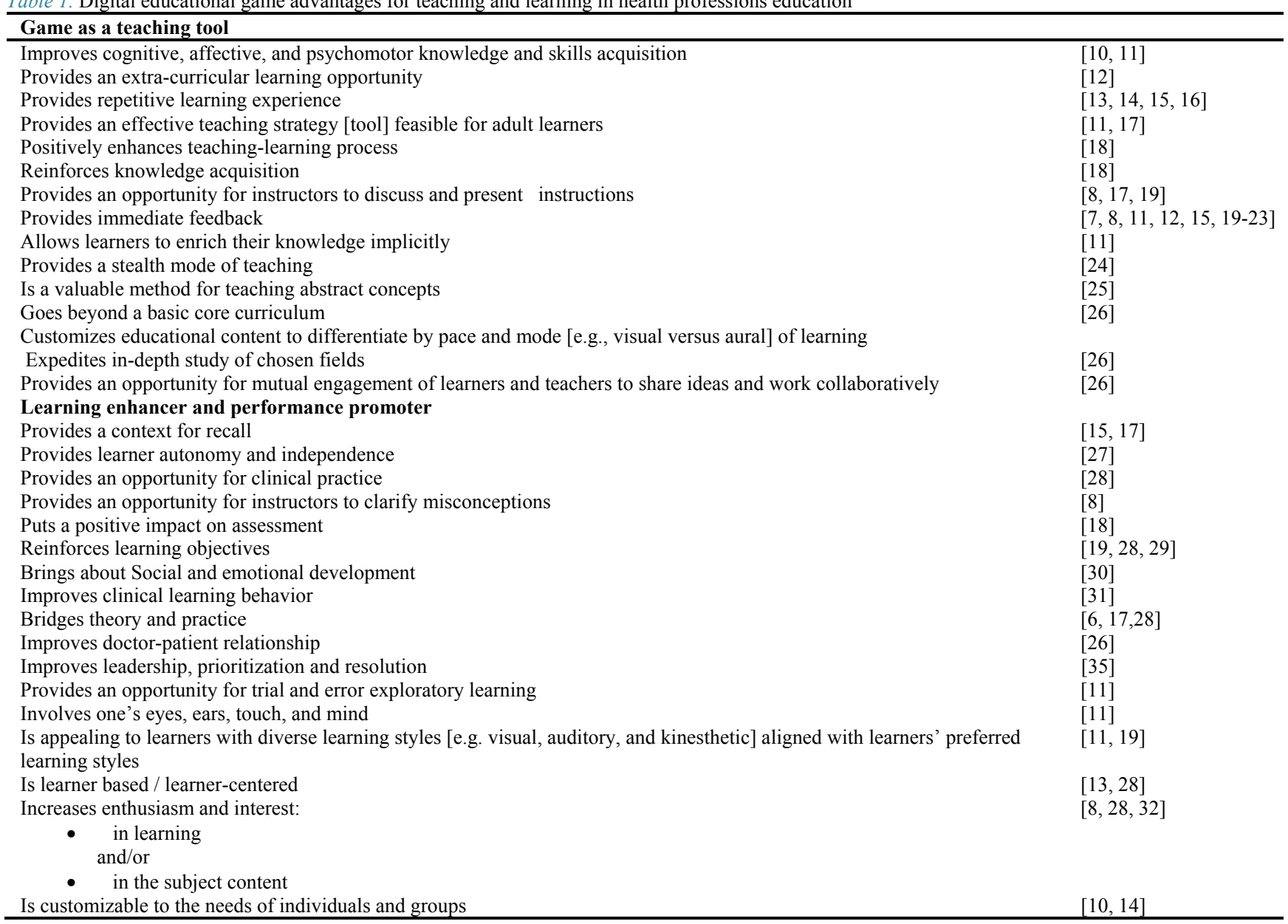




\begin{tabular}{|c|c|}
\hline $\begin{array}{l}\text { Provides a novel opportunity for the learners to: } \\
\text { - Contextualize information } \\
\text { and } \\
\text { - Study the consequences of their choices }\end{array}$ & {$[11]$} \\
\hline \multicolumn{2}{|l|}{ Practical benefits Provider } \\
\hline Provides an outcome or goal oriented opportunity & {$[6,20]$} \\
\hline Provides structured and ruled context activity & {$[7,9,21,29]$} \\
\hline Provides a reward system & {$[17,23]$} \\
\hline Includes briefing and debriefing & {$[23]$} \\
\hline Improves knowledge retention & {$[32]$} \\
\hline Is cheaper than traditional teaching methods & {$[24]$} \\
\hline Enhances learning and teamwork & {$[32]$} \\
\hline Improves problem-solving & {$[11,19,28,29]$} \\
\hline Enhances stress management & [33] \\
\hline \multicolumn{2}{|l|}{ Motivation/ Interest Enhancer } \\
\hline Provides a learning variety & {$[6]$} \\
\hline Leads to positive emotions and emotional stability & {$[27,34]$} \\
\hline Helps better attachment to educational settings & [34] \\
\hline Holds learner-oriented/ or centered approach & {$[6,24,29]$} \\
\hline
\end{tabular}

teaching and learning. A digital educational game has several advantages; for example, as a teaching tool, it is feasible for adult learning, and provides an opportunity for experiential repetitive learning. Furthermore, engaging learners enhances the acquisition of knowledge, attitude, and practice, allows learner individualization, improves learning process and learning outcomes, and provides practical benefits for teachers, learners, and health system target audience. Application of digital educational games provides a safe virtual curricular and extracurricular educational space beyond ordinary teaching and learning contexts for more collaboration between teachers and learners. Moreover, if digital games are adopted successfully they could improve patient-practitioner relationship (Table 1).

In contrast, the literature we reviewed has depicted a number of disadvantages for using digital games in a teaching and learning process; however, most of these disadvantages are only mentioned in one citation. Due to their competitive nature and production expensiveness, games are reported to be threatening and intimidating for some learners. Interdisciplinary expert dependency, time- consuming nature, and learning style dependency were other disadvantages mentioned in the literature. Other disadvantages, although important, were mentioned only once or twice. These were boredom potential, lack of widely accepted guidelines, learners' lack of desire to cooperate leading to game failure, and potential negative reaction of learners to the game design, and thereby requiring teacher and student training (Table 2).

The aforementioned factors all fall under 2 major subcategories of disadvantages; the first one denotes the logistics of developing a digital game; i.e., interdisciplinary expert and participant dependency, lack of widely accepted guidelines, required training, and most importantly cost, and time. The second subcategory includes factors related to teaching and learning processes such as threatening and intimidating, learning style dependency, boredom potential, and negative reaction of learners to the game.

In addition to the above-mentioned disadvantages, our own game experience indicates that the potential of physical harm to game players is highly critical. Physical posture of the player during the gameplay and sitting stand still for a long period of time will jeopardize musculoskeletal health of the players. Moreover, digital game players experience physiological changes related to stress (eustress or distress) under the game conditions, which are similar to signs and symptoms of stress in other situations; e.g. muscular ten-

Table 2. Digital game disadvantages for teaching and learning in health professions education

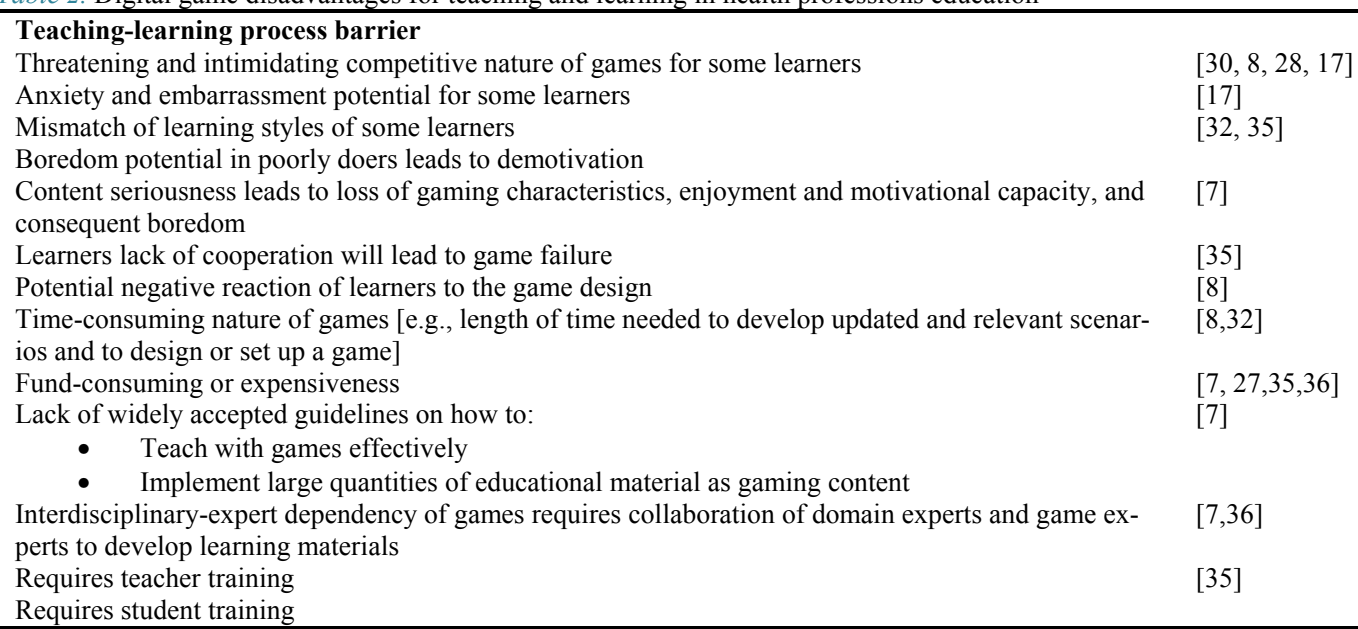




\begin{tabular}{|c|c|}
\hline \multicolumn{2}{|l|}{ Cognitive Skills } \\
\hline Attention [focus] & {$[6,33]$} \\
\hline Parallel & [11] \\
\hline Visual & {$[33,34]$} \\
\hline \multicolumn{2}{|l|}{ Thinking } \\
\hline Critical & {$[6,8,10,16,17,28,30,35,42]$} \\
\hline Creative & {$[21,35]$} \\
\hline Positive & [21] \\
\hline Strategic & {$[11,34]$} \\
\hline Reflective & [43] \\
\hline Interpretive analysis & [11] \\
\hline Reasoning & {$[8,10,33,35]$} \\
\hline Decision-making & {$[6,8,44]$} \\
\hline Problem-solving & {$[10,19,20,21,34,36]$} \\
\hline Mental challenge & {$[6,11,13,15,22,29,36]$} \\
\hline Intrigue/ curiosity & {$[21,36]$} \\
\hline Knowledge reinforcement & [17] \\
\hline Active learning & {$[7,8,15,16,28,35]$} \\
\hline Deep learning & [8] \\
\hline \multicolumn{2}{|l|}{ Planning } \\
\hline Spatial creativity & [33] \\
\hline Meta cognition & {$[10]$} \\
\hline \multicolumn{2}{|l|}{ Affective Skills } \\
\hline Participation & {$[9,8,12,6,22]$} \\
\hline Motivation & {$[6,7,11,12,15,20,23,32-34,36]$} \\
\hline Absorption & {$[6,7,8,11,16,20,22,24,32]$} \\
\hline \multicolumn{2}{|l|}{ Enjoyment } \\
\hline \multicolumn{2}{|l|}{ Fun to play } \\
\hline \multicolumn{2}{|l|}{ Psychomotor Skills } \\
\hline Improved technical skills for procedures & {$[22]$} \\
\hline \multicolumn{2}{|l|}{$\begin{array}{l}\text { Interaction Skills } \\
\text { Inter }\end{array}$} \\
\hline Peer learning & {$[6]$} \\
\hline Social interaction[fabric], communication, and networking & {$[6,7,8,11,12,15,17,20,21,22,26,28,29,30,35,36,43]$} \\
\hline Collaborative, cooperative, and interactive learning & {$[13,6,30,43,20,22,26,21,8,15,29,28,11,35]$} \\
\hline Competition [team and individual/ self-directed] & {$[6,2012,30,36,22,15,7,17]$} \\
\hline Self- and team- efficacy & {$[43]$} \\
\hline \multicolumn{2}{|l|}{ Psychosocial functioning } \\
\hline \multicolumn{2}{|l|}{ Self-confidence } \\
\hline \multicolumn{2}{|l|}{ Happiness } \\
\hline Relaxation & [33] \\
\hline Achievement motivation & \\
\hline Empathy & \\
\hline
\end{tabular}

sion, dry mouth, clinging of fingers, pressure on jaws, palpitation, etc. (37). Moreover, in some cases, psychological game-dependency of game players is similar to internet addiction and individual game play limits social interaction and encourages individualism and isolation. Furthermore, the philosophy of gameplay is not a matter of discussion in designing educational games. In cases that the game character experiences emotions (e.g. pain, difficulty, pressure, anxiety, etc.), the vibes permeate to the player and s/he experiences the same emotional status; in other words, the gameplay emotion is transferred to the player due to identification of educational game player and game characters.

Digital educational games by recruiting learner engagement factors (Table 3 ) and increasing energy level of players (6) positively influence cognitive, affective, and psychomotor skills of learners and actively engage them in the learning process $(11-13,15,19,22,27,28,32,33,36)$. In addition, digital educational games, by improving visual memory/processing (33) and higher level thinking (38) of the game players, reinforce their analysis, synthesis, and evaluation competencies (39), reframe their identities and

Table 4. Educational game engagement factors: Game dependent

\begin{tabular}{ll}
\hline Game safety & \\
\hline Safe learning environment & {$[25,10,17]$} \\
Chance [uncertainty, surprise, risk, and randomness] & {$[6]$} \\
Pride in achievement or accomplishment & {$[6]$} \\
Prize [reward] & {$[6,23,11,33]$} \\
Humor & {$[6,36,35]$} \\
Surprise & {$[6]$} \\
Excitement & {$[32,22]$} \\
Fun & {$[24,6,22,8,7,22,32,35]$} \\
Fantasy & {$[6]$} \\
\hline
\end{tabular}


interests to their professional community of practice (40), and help them develop empathy (33) ethical and professional understanding of action and interaction in medical settings (40) or health profession communities. Digital educational games can be customized according to the pace and mode of learning in each individual (25), and since the medical curriculum could not be prescribed with the same magnitude for each learner (41), their application is a vehicle leading to a unique learning experience. Accordingly, based on the existing literature, we divided the game engagement factors to learner-dependent (Table 3) and gamedependent (Table 4).

Providing a safe educational environment is a promise of educational games for health professions education. It permits practice of what is really impossible or undesirable in real time and in a virtual world (16). Moreover, an educational game for health professions education positively enhances teaching and learning process and is to the benefit of students with diverse learning styles (e.g. visual and au$\mathrm{ral}$, read/write, and kinesthetic) (45).

\section{Conclusion}

This paper is a comprehensive review of the existing literature on digital educational games, with a specific focus on health professions education, addressing specific aspects of digital educational games including game advantages, disadvantages, and engagement factors. The findings of this study suggest that as a teaching tool, advantages of digital educational games can be categorized as learning process enhancers, learning and performance improver, and individualized learning provider, holding practical benefits and learners' motives. However, disadvantages of digital educational games can be categorized into teaching-learning process barriers and logistics of educational games. Finally, it is recommended that psycho-physio-philosophical aspects of learning be considered in digital game play contexts in another study.

\section{Study strengths and weaknesses}

The major strengths of this review study include a comprehensive search strategy, duplicate and independent screening of papers according to the titles and abstracts, retrieval and review of the full texts of all potentially eligible papers related to digital games in medicine, nursing, dentistry, and pharmacy published in English language. Moreover, classification of digital educational games based on advantages and disadvantages of using digital educational games in the teaching and learning process focused on health professions education and game engagement factors are other strong points of this study.

The weaknesses of the study were related to the limited scope of the review as the papers were reviewed during 2010 and 2015. Moreover, the conclusions do apply to types of interventions, sometimes labelled as games, such as role play, simulations, and serious games because their margins are blurred and to the best of our knowledge there is no clear cut-off point to discriminate them.

Even though rigorous attempts were made to ensure the audience that this review covered all articles on educational digital games in the given disciplines, some papers might have been missed. Nevertheless, this limitation does not influence the frequency of advantages and disadvantages of digital educational games reported in the literature.

Finally, it is suggested that a team of curriculum designers, educational psychologists, cognitive psychologists, educational philosophers, physiologists, technical game designers, and content and game experts work together to develop an educational game in health professions education.

\section{Acknowledgements}

Funding of this paper was provided by AGE-WELL National Centre of Excellence (Project WP4.2)

\section{Conflict of Interests}

The authors declare that they have no competing interests.

\section{References}

1.http://www.instituteofplay.org/about/context/history-of-games-learn ing/

2. Sauvé L, Renaud L, Kaufman D, Marquis JS. Distinguishing between games and simulations: A systematic review. J Educ Techno Soc. 2007 Jul 1;10(3):247-56.

3. Rutter J, Bryce J, editors. Understanding digital games. Sage; 2006 Apr 20.

4. Sauvé L, Renaud L, Kaufman D. Games, simulations and simulations games for learning: Definitions and distinctions. D. Kaufman \& L. Sauvé. Educational gameplay and simulation environments: Case studies and lessons learned. 2010 Jan 31:1-26

5. Bigdeli S, Kaufman D. Digital games in medical education: Key terms, concepts, and definitions. Med J Islam Repub Iran. 2017(2 Sep);31:52.https://doi.org/10.18869/mjiri.31.52

6. Pettit RK, McCoy L, Kinney M, Schwartz FN. Student perceptions of gamified audience response system interactions in large group lectures and via lecture capture technology. BMC medical education. 2015 May 22;15(1):92.

7. Boeker M, Andel P, Vach W, Frankenschmidt A. Game-based e-learning is more effective than a conventional instructional method: a randomized controlled trial with third-year medical students. PloS one. 2013 Dec 5;8(12):e82328.

8. Boctor L. Active-learning strategies: the use of a game to reinforce learning in nursing education. A case study. J Nurs Educ Pract. 2013 Mar 31;13(2):96-100.

9. Akl EA, Pretorius RW, Sackett K, Erdley WS, Bhoopathi PS, Alfarah $Z$, et al. The effect of educational games on medical students' learning outcomes: a systematic review: BEME Guide No 14. Med teach. 2010 Jan 1;32(1):16-27

10. dit Dariel OJ, Raby T, Ravaut F, Rothan-Tondeur M. Developing the Serious Games potential in nursing education. Nurse educ today. 2013 Dec 31;33(12):1569-75.

11. Kanthan R, Senger JL. The impact of specially designed digital games-based learning in undergraduate pathology and medical education. Arch of pathol \& lab med. 2011 Jan;135(1):135-42.

12. Nevin CR, Westfall AO, Rodriguez JM, Dempsey DM, Cherrington A, Roy B, etal. Gamification as a tool for enhancing graduate medical education. Postgrad Med J. 2014 Dec;90(1070):685-93. doi: 10.1136/postgradmedj-2013-132486. Epub 2014 Oct 28.

13. Dankbaar ME, Alsma J, Jansen EE, van Merrienboer JJ, van Saase JL, Schuit SC. An experimental study on the effects of a simulation game on students' clinical cognitive skills and motivation. Adv Health Sci Educ. 2016 Aug 1;21(3):505-21.

14. Cant RP, Cooper SJ. Simulation in the Internet age: The place of Web-based simulation in nursing education. An integrative review. Nurse educ today. 2014 Dec 31;34(12):1435-42.

15. Müller A. Research-based design of a medical vocabulary videogame. International Journal of Pedagogies and Learning. 2012 Nov 1;7(2):122-34.Nevin CR, Westfall AO, Rodriguez JM, Dempsey DM, Cherrington A, Roy B, Patel M, Willig JH. Gamification as a tool for 
enhancing graduate medical education. Postgrad. med journal. 2014 Dec 1;90(1070):685-93.

16. Alfarah Z, Schünemann HJ, Akl EA. Educational games in geriatric medicine education: A systematic review. BMC geriatr. $2010 \mathrm{Apr}$ 23;10(1):19.

17. Blakely G, Skirton H, Cooper S, Allum P, Nelmes P. Use of educational games in the health professions: A mixed-methods study of educators' perspectives in the UK. Nurs \& health scie. 2010 Mar $1 ; 12(1): 27-32$

18. Abdulmajed H, Park YS, Tekian A. Assessment of educational games for health professions: a systematic review of trends and outcomes. Med teach. 2015 Mar 13;37(sup1):S27-32.

19. Nicolaidou I, Antoniades A, Constantinou R, Marangos C, Kyriacou $\mathrm{E}$, Bamidis $\mathrm{P}$, et al. A virtual emergency telemedicine serious game in medical training: a quantitative, professional feedback-informed evaluation study. J. of med. Internet res. 2015 Jun;17(6).

20. Gleason AW. RELM: Developing a serious game to teach evidencebased medicine in an academic health sciences setting. Med ref serv q. 2015 Jan 2;34(1):17-28.

21. Fonseca LM, Dias DM, Góes FD, Seixas CA, Scochi CG, Martins JC, Rodrigues MA. Development of the e-Baby serious game with regard to the evaluation of oxygenation in preterm babies: contributions of the emotional design. CIN: ComputInform, Nurs. 2014 Sep 1;32(9):428-36

22. Yunyongying P. Gamification: implications for curricular design. JGrad Med Educ. 2014 Sep;6(3):410-2.

23. Joseph S, Diack L. Playing interprofessional games: reflections on using the Interprofessional Education Game (iPEG). J Interprof Care. 2015 May 4;29(3):260-2.

24. Ricciardi F, Paolis LT. A comprehensive review of serious games in health professions. IJCGT. 2014 Jan 1;2014:9.

25. Chen AM, Kiersma ME, Yehle KS, Plake KS. Impact of an aging simulation game on pharmacy students' empathy for older adults. Am Journal of Pharm Educ. 2015 Jun 25;79(5):65.

26. Colbert JA, Chokshi DA. Technology in medical education-Osler meets Watson. Cook NF, McAloon T, O'Neill P, Beggs R. Impact of a web based interactive simulation game (PULSE) on nursing students' experience and performance in life support training-A pilot study. Nurse educ today. 2012 Aug 31;32(6):714-20.

27. Moreno-Ger P, Torrente J, Bustamante J, Fernández-Galaz C, Fernández-Manjón $\mathrm{B}$, Comas-Rengifo $\mathrm{MD}$. Application of a low-cost web-based simulation to improve students' practical skills in medical education. Int Med Inform. 2010 Jun 30;79(6):459-67.

28. Carifa L, Goodin HJ. Using games to provide interactive perioperative education. AORN j. 2011 Oct 31;94(4):370-6.

29. Hannig A, Kuth N, Özman M, Jonas S, Spreckelsen C. eMedOffice: A web-based collaborative serious game for teaching optimal design of a medical practice. BMC med educ. 2012 Oct 31;12(1):104.

30. Aburahma MH, Mohamed HM. Educational games as a teaching tool in pharmacy curriculum. Am j pharmaeduc. 2015 May 25;79(4):59.

31. Kerfoot BP, Baker H, Pangaro L, Agarwal K, Taffet G, Mechaber AJ, et al. An online spaced-education game to teach and assess medical students: a multi-institutional prospective trial. Acad Med. 2012;87(10):1443-1449.

32. Stanley D, Latimer K. 'The Ward': A simulation game for nursing students. Nurse Educ in Pract. 2011 Jan 31;11(1):20-5.

33. Kato PM. Video games in health care: Closing the gap. Review of General Psychology. 2010 Jun;14(2):113.Kerfoot BP, Baker H. An online spaced-education game to teach and assess residents: a multiinstitutional prospective trial. J Am Coll Surg. 2012 Mar 31;214(3):367-73

34. Rodriguez DM, Teesson M, Newton NC. A systematic review of computerised serious educational games about alcohol and other drugs for adolescents. Drug and alcohol rev. 2014 Mar 1;33(2):129-35.

35. Baid H, Lambert N. Enjoyable learning: the role of humour, games, and fun activities in nursing and midwifery education. Nurse Educ Today. 2010;30(6):548-552.

36. Torrente J, Borro-Escribano B, Freire M, del Blanco Á, Marchiori EJ, Martínez-Ortiz I, et al. Development of game-like simulations for procedural knowledge in healthcare education. IEEE Trans. Learn.Technol. 2014 Jan;7(1):69-82.

37. Bigdeli S, Bai H. The triunal model of anxiety and its application to anxiety reduction in learning and teaching environments. TESL Canada J. 2009 Dec 18;27(1):103-14.

38. Begg M. Leveraging game-informed healthcare education. Med
Teach. 2008 Jan 1;30(2):155-8.

39. Akl EA, Mustafa R, Slomka T, Alawneh A, Vedavalli A, Schünemann HJ. An educational game for teaching clinical practice guidelines to Internal Medicine residents: development, feasibility and acceptability. BMC med educ. 2008 Nov 18;8(1):50.

40. Kron FW, Gjerde CL, Sen A, Fetters MD. Medical student attitudes toward video games and related new media technologies in medical education. BMC MedEduc. 2010 Jun 24;10(1):50.

41. Norman G. Research in medical education: three decades of progress. Bmj. 2002 Jun 29;324(7353):1560-2. Oblinger D, Oblinger JL, Lippincott JK. Educating the net generation. Boulder, Colo.: EDUCAUSE, c2005. 1 v.(various pagings): illustrations.; 2005.

42. Dunne JR, McDonald CL. Pulse!!: A model for research and development of virtual-reality learning in military medical education and training. Mil. med. 2010 Jul 2;175.

43. Shin S, Park JH, Kim JH. Effectiveness of patient simulation in nursing education: meta-analysis. Nurse educ today. 2015 Jan 31;35(1):176-82.

44. Cook NF, McAloon T, O'Neill P, Beggs R. Impact of a web based interactive simulation game (PULSE) on nursing students' experience and performance in life support training-A pilot study. Nurse Educ Today. 2012;32(6):714-720.

45. Bigdeli S, Kaufman D. Digital games in medical education: Key terms, concepts, and definitions. Med J Islam Repub Iran. 2017(2 Sep);31:52. 